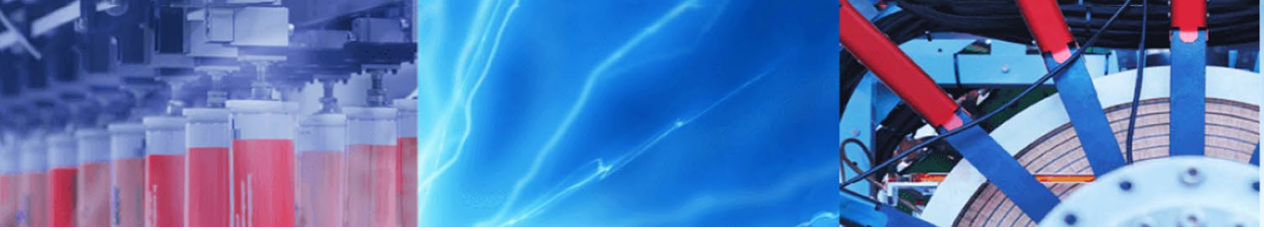

Research Article

\title{
Preparation of tungstic acid functionalized titanium oxide nanotubes and its effect on proton exchange membrane fuel cell
}

\author{
Vijayakumar Elumalai ${ }^{1} \cdot$ Thirunavukarasu Deenadhayalan $^{1}$ - A. Kathleen Asitha ${ }^{1}$. David Joel Kirubhakaran ${ }^{1}$. \\ Dharmalingam Sangeetha' ${ }^{1}$ (1)
}

(c) Springer Nature Switzerland AG 2019

\begin{abstract}
Titanium oxide nano tubes (TNT) were synthesized by hydrothermal method and tungstic acid (ion exchange group) were covalently grafted on its surface. The synthesized tungstic acid functionalized TNT (W-TNT) were characterised by SEM, TEM, XRD analysis for the nano-tubular morphology and the successful grafting of tungstic acid group was confirmed by FTIR and solid state NMR techniques. Composite membranes of different weight percentage W-TNT ( $2 \%, 4 \%, 6 \%$ and $8 \%$ ) and sulfonated poly ether ether ketone (SPEEK) were fabricated which resulted in high ion exchange properties. The prepared composite membranes were characterised by SEM, XRD, FTIR, water uptake, ion exchange capacity and proton conductivity to ensure the aptness of the membranes to be used as electrolyte in fuel cell application. From the studies it was found that SPEEK with 6\% W-TNT showed optimum electrochemical properties. Upon testing this membrane in fuel cell as an electrolyte with carbon supported platinum anode and cathode electrodes, a maximum power density of $352 \mathrm{~mW} \mathrm{~cm}{ }^{-2}$ was achieved at $80^{\circ} \mathrm{C}$. The presence of additional ion exchange groups (tungstic acid) and hollow nature of TNT lead to the improved performance than the plain membrane.
\end{abstract}

Keywords Titanium oxide nano tubes · Tungstic acid functionalization · Nanocomposite membranes $\cdot$ Sulfonated polymer · Polymer electrolyte

\section{Introduction}

Recently, more attention is being paid in harvesting energy from renewable and eco-friendly resources, as pollution keeps increasing with energy obtained from non-renewable sources [1]. As a result, fuel cells have become more popular as it produces energy from fuel and oxidant with high efficiency and almost zero emission [2]. Amongst the different types of fuel cells available, proton exchange membrane fuel cells (PEMFCs) are advantageous due to their unique features such as low-operating temperature, sustained operation at high-current density, low weight, compact and high efficiency [3]. Nafion, (commercially available proton conducting membrane) is widely used in PEMFC due to its high proton conductivity, good mechanical, chemical and thermal stability. But its high cost, high fuel cross over behaviour and fluorine backbone (non eco-friendly) makes it a serious disadvantage while using as an electrolyte in PEMFC [4]. So, researchers have been working on developing cost efficient and ecofriendly polymer membranes consisting of hydrocarbon backbone. High engineering polymers such as poly ether ether ketone (PEEK) [5], Poly styrene-ethylene-butylenestyrene (PSEBS) [6], poly(ether sulfone) (PES) [7], polyimide (PI) [8], poly vinyl imidazole (PVIM) [9], polyphenylene (PPE) [10] and polybenzimidazole (PBI) [11], etc. have been subjected to modification (sulfonation) to replace Nafion [12].

Among these membranes, sulphonated PEEK (SPEEK) has been widely studied than other membranes, due to

$\triangle$ Dharmalingam Sangeetha, sangeetha@annauniv.edu | 'Department of Mechanical Engineering, Anna University, Chennai 600025, India.

SN Applied Sciences (2019) 1:348 | https://doi.org/10.1007/s42452-019-0358-y 
its good thermo-mechanical stability and decent conductivity $[13,14]$. But these properties were inferior to that of Nafion. Hence, to improve the overall properties of the SPEEK, nano inorganic fillers like $\mathrm{TiO}_{2}$ [15], $\mathrm{ZrO}_{2}$ [16] and $\mathrm{SiO}_{2}$ [17], $\mathrm{SnO}_{2}$ [18], $\mathrm{WO}_{3}$ [19] were incorporated into the SPEEK membrane. From these research studies it was revealed that the addition of nano particles increases hydrophilic nature and provides a preferential path for protons transfer through water molecules (Grotthuss mechanism). Moreover, the high specific surface area of nano particles increases the interface interaction with the polymer and thereby increases the thermo-mechanical stabilities [20,21]. Two dimensional (2D) nano structured materials like nano tubes, nano rods or fibres have an additional advantage of reduced fuel crossover due to the very large specific surface area and anisotropic structure [13]. Among various $2 \mathrm{D}$ materials, $\mathrm{TiO}_{2}$ nano tubes are stable and eco-friendly, and its electronic, optical, and dielectric properties can be tuned by surface modifications [22, 23]. Hence $\mathrm{TiO}_{2}$ nano tubes based composite membranes were developed and reported [24, 25]. Furthermore, sulphonated $\mathrm{TiO}_{2}$ [ion exchange groups on the surface of the $\mathrm{TiO}_{2}$ nano tubes (TNT)] were also employed as filler in preparing the composite membrane and has been proven that its properties were superior to the un-functionalized filler [26].

In the present study, tungstic acid was covalently bonded with titanium oxide nano tubes (W-TNT) and used as an ion exchange filler for the first time for fabricating the proton exchange composite membranes. Tungstic acid group $\left(\mathrm{H}_{2} \mathrm{WO}_{4}\right)$ has also containing exchangeable protons similar sulfonic acid group $\left(\mathrm{SO}_{3} \mathrm{H}\right)$ which could also act as an ion exchanger. Hence tungstic acid group has been recommended to be used as ion exchange material for the conduction of proton. Grafting of tungstic acid groups on the surface of $\mathrm{TiO}_{2}$ nano tubes, is expected to assist both the Grotthuss and hopping mechanisms of ion conductivity. Nano composite membranes were prepared consisting of various concentrations of the filler $(2 \%, 4 \%$, $6 \%, 8 \%)$ in SPEEK matrix and the effect of feed ratio was evaluated in terms of water uptake, proton conductivity and ion exchange capacity.

\section{Materials and methods}

PEEK was obtained from Victrex, Titanium powders $(99.7 \%$ purity) and Disodium Tungstate ( $\geq 99 \%$ purity) were received from Sigma Aldrich. 3-chloropropyltrimethoxysilane ( $\geq 97 \%$ purity) was acquired from Alfa Aesar, solvents like ethanol ( $\geq 99.5 \%$ purity), NMP ( $99.5 \%$ purity), n-hexane (99\% purity) were obtained from E-Merck. All the chemicals were directly used without subjecting to any purification process.

\subsection{Preparation of SPEEK}

Synthesis of SPEEK has been reported in our earlier research work [25] and the same methodology was carried out. About $10 \mathrm{~g}$ of PEEK was gradually dissolved in $150 \mathrm{~mL}$ conc. $\mathrm{H}_{2} \mathrm{SO}_{4}$ under nitrogen atmosphere. The reaction mixture was subjected to constant magnetic stirring for $8 \mathrm{~h}$. Then the reaction was terminated with ice cubes and washed with distilled water until $\mathrm{pH}$ became neutral. The obtained polymer was then dried at $80^{\circ} \mathrm{C}$ in a vacuum hot oven for $24 \mathrm{~h}$.

\subsection{Synthesis of tungstic acid functionalized titanium oxide nano tubes (W-TNT)}

\subsubsection{Synthesis of titanium oxide nano tubes (TNT)}

Titanium oxide nano tubes were synthesized by hydrothermal method as per the procedure [27]. About $4.375 \mathrm{~g}$ of $\mathrm{TiO}_{2}$ powder was added to $200 \mathrm{~mL}$ of $10 \mathrm{M} \mathrm{NaOH}$ solution and stirred magnetically for $30 \mathrm{~min}$ followed by sonication for $30 \mathrm{~min}$. The reaction was carried out at $140{ }^{\circ} \mathrm{C}$ in Teflon lined autoclave for $24 \mathrm{~h}$. The obtained solution was washed with distilled water and neutralized with $1 \mathrm{M} \mathrm{HCl}$. Finally, TNT powders were obtained by vacuum filtration.

\subsubsection{Chloromethylation of TNT (Cl-TNT)}

About $2.5 \mathrm{~g}$ of TNT was added into $250 \mathrm{~mL}$ of ethanol and sonicated for $1 \mathrm{~h}$ for complete dispersion. To this, $20 \mathrm{ml}$ of 3-Chloropropyltrimethoxysilane was added dropwise and sonication was continued for another $1 \mathrm{~h}$. Then the reaction mixture was heated to $120^{\circ} \mathrm{C}$ using an oil bath and maintained for $48 \mathrm{~h}$ under nitrogen atmosphere with continuous stirring. After the set time, the reaction crude was subjected to centrifugation process and the obtained $\mathrm{Cl}$ TNT powder was dried at $80^{\circ} \mathrm{C}$ in a vacuum oven $[16,28]$.

\subsubsection{Preparation of tungstic acid functionalized TNT (W-TNT)}

Tungstic acid functionalization of TNT was carried out based on literature [28]. About $2 \mathrm{~g}$ of $\mathrm{Cl}$-TNT powder and $4 \mathrm{~g}$ of di sodium tungstate $\left(\mathrm{Na}_{2} \mathrm{WO}_{4}\right)$ was added to $50 \mathrm{~mL}$ of $\mathrm{n}$-hexane and sonicated for $2 \mathrm{~h}$. The reaction was carried out at room temperature $\left(30^{\circ} \mathrm{C}\right)$ for $12 \mathrm{~h}$ under continuous magnetic stirring. The reaction mixture was then centrifuged and washed with distilled water. The obtained powder was dried and stirred magnetically in the presence of $20 \mathrm{~mL}$ aqueous $\mathrm{HCl}$ for $1 \mathrm{~h}$ for the hydrolysis of sodium 
tungstate. The solution was washed with distilled water and followed by centrifugation to obtain W-TNT powder (Fig. 1).

\subsection{Synthesis of composite membrane}

SPEEK was dissolved completely in NMP, then various weight percentages $(2 \%, 4 \%, 6 \%$, and $8 \%$ ) of W-TNT were added and stirred for $48 \mathrm{~h}$ followed by sonication for $30 \mathrm{~min}$ to attain maximum dispersion. The solutions were poured into a clean, dry petri dish of same size and placed in the vacuum oven at $80^{\circ} \mathrm{C}$. The membranes were solidified upon the evaporation of the solvent. After solidification, the membranes were retrieved from the petri dish and washed with deionized water to remove any residual solvent present in it. The obtained membranes were designated as SPEEK, SPEEK 2\% W-TNT, SPEEK 4\% W-TNT, SPEEK $6 \%$ W-TNT and SPEEK $8 \%$ W-TNT based upon the percentage of the functionalized fillers added.

\subsection{Preparation of membrane electrode assembly (MEA) and fuel cell performance}

To fabricate the membrane electrode assembly (MEA), anode and cathode were prepared separately which was described in our previous work [17]. The typical mass loading of the Pt on cathode and anode were $0.375 \mathrm{mg} \mathrm{cm}^{-2}$ and $0.25 \mathrm{mg} \mathrm{cm}^{-2}$ respectively. Then the composite membrane was sandwiched between the two electrodes and was hot pressed for $2 \mathrm{~min}$ at $80^{\circ} \mathrm{C}$ under 1.5-ton pressure. The fuel cell performance was obtained in lab made PEM fuel cell with an active surface area of $25 \mathrm{~cm}^{2}$ at $80^{\circ} \mathrm{C}$. Highly pure hydrogen (99.994\%) and oxygen (99.9\%) gas was made to flow through the cell under controlled condition at 600 SCCM and 300 SCCM for cathode and anode respectively under $80 \%$ humidity.

Fig. 1 Synthesis of W-TNT

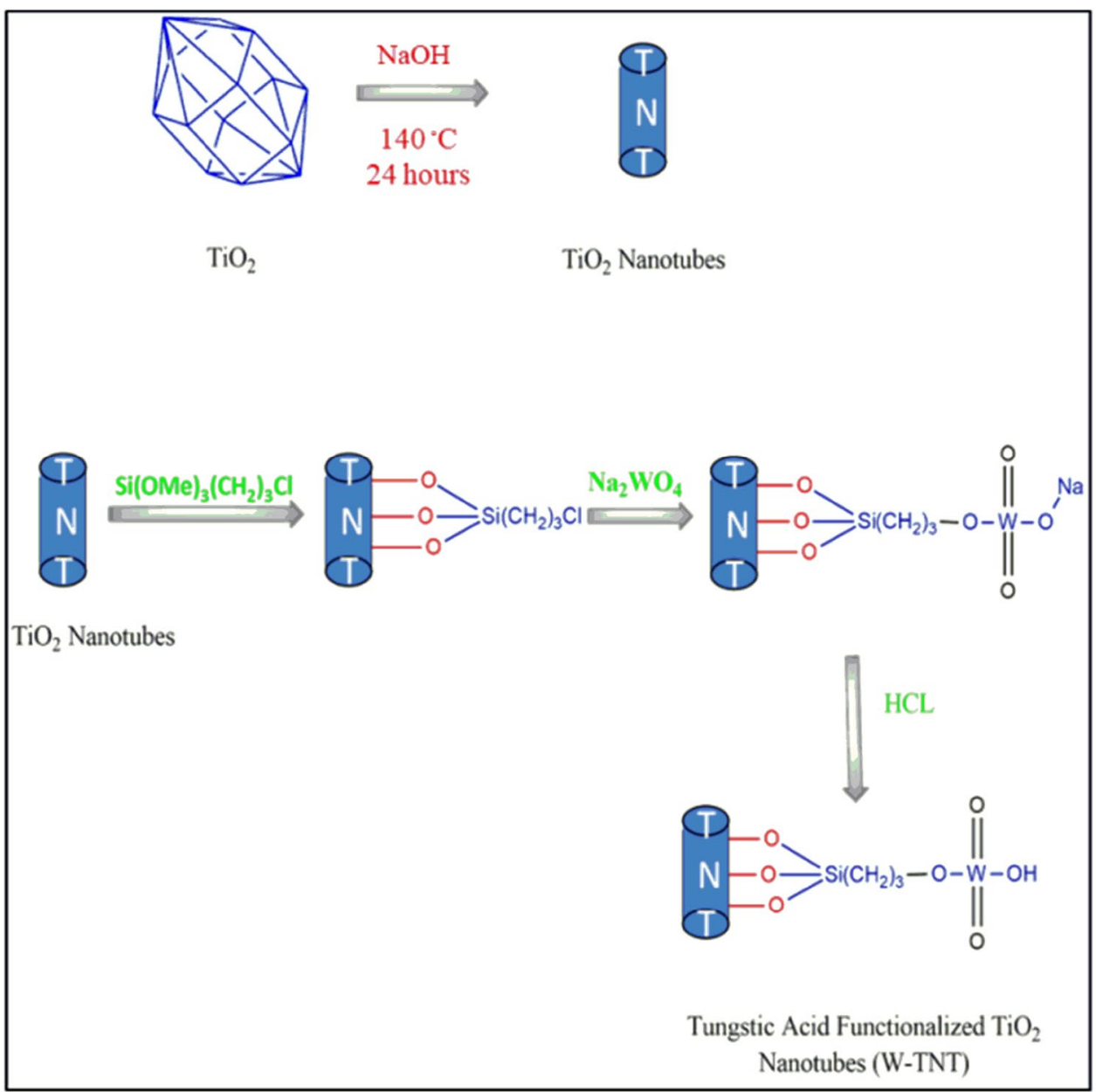




\subsection{Instrumental characterization}

\subsubsection{Fourier transform infrared spectroscopy (FTIR)}

The synthesized TNT and composite membranes were characterised using FTIR using Alpha Bruker T spectrometer for the functional groups identification and the interaction between polymer and fillers. The samples were scanned for the wave number from 500 to $4000 \mathrm{~cm}^{-1}$. The synthesized TNT materials were pelletized and scanned in transmittance mode using $\mathrm{KBr}$ while the membranes were analysed in ATR mode.

\subsubsection{Scanning electron microscopy (SEM)}

The surface morphology of the TNT and dispersion of W-TNT in the SPEEK matrix were examined using SEM (JEM-5600LV) with $30 \mathrm{kV}$ accelerating voltage. All the samples were subjected to gold ion sputtering before analysis,

\subsubsection{X-ray diffraction (XRD)}

The synthesized TNT and W-TNT were analysed by XRD to confirm its tubular morphology and the crystalline nature of the prepared composite membranes were also studied. The analysis was performed using X'Pert Pro diffractometer at a scanning rate of $2^{\circ}$ per minute between two theta range of $5^{\circ}-70^{\circ}$.

\subsubsection{Transmission electron microscopy (TEM)}

The hollow nature of the TNT and W-TNT were confirmed on examining the synthesized samples using TEM (Tecnai T30) with $300 \mathrm{kV}$ accelerating voltage and a resolution of $2 \mathrm{~mm}$.

\subsubsection{Proton conductivity}

Resistance of the membranes was analysed by AC impedance spectroscopy using two electrode method at room temperature. Then conductivity was calculated using Eq. 1:

$\sigma=\frac{L}{R X A}\left(\mathrm{~S} \mathrm{~cm}^{-1}\right)$

where $\sigma=$ proton conductivity, $L=$ membrane thickness in $\mathrm{cm}, \mathrm{R}=$ membrane resistance $(\Omega)$, and $A=$ membrane area $\left(\mathrm{cm}^{2}\right)$. Before the experiment, all the samples were immersed in water for $24 \mathrm{~h}$ for hydration [17].

\subsection{6 lon exchange capacity (IEC)}

Ion exchange capacity (IEC) is the capability of an insoluble material be subjected to displacement of ions and was determined by classical back titration technique. The membranes were soaked in $2 \mathrm{M} \mathrm{KCl}$ for $24 \mathrm{~h}$ to ensure the complete replacement of $\mathrm{H}^{+}$ions by $\mathrm{K}^{+}$ions. Sodium carbonate solution of known concentration was then titrated against the supplanted $\mathrm{H}^{+}$ions with a few drops of phenolphthalein indicator. [29]. IEC was calculated from the following Eq. 2:

IEC $=\frac{\text { Titre value }(\mathrm{ml}) \times \text { Normality of } \mathrm{Na}_{2} \mathrm{CO}_{3}}{\text { Weight of dry membrane }(\text { in } \mathrm{g})}$ meq $^{-1}$

\subsubsection{Water uptake}

Water uptake of the membranes was examined by gravimetrically by measuring weight of the dry and wet membranes. The accurately weighed dry membranes of size $(1 \mathrm{~cm} \times 1 \mathrm{~cm})$ were submerged in distilled water for $24 \mathrm{~h}$. The wet weight of the hydrated membrane was measured quickly after removing excess water on the surface of the membrane [25]. The percentage of water uptake was calculated using Eq. 3 given below:

water uptake percentage

$$
\begin{aligned}
= & \frac{\text { wt.of wet polymer }- \text { wt.of dry polymer }}{\text { wt.of dry polymer }} \\
& \times 100 \%
\end{aligned}
$$

\subsubsection{Nuclear magnetic resonance (NMR) spectroscopy}

The successful sulphonation of PEEK and the degree of sulphonation were determined by ${ }^{1} \mathrm{H}$ NMR and the effective covalent bond formation between the TNT surface and $\mathrm{Si}\left(\mathrm{CH}_{2}\right)_{3} \mathrm{WO}_{4} \mathrm{H}$ (tungstic acid group) was confirmed using CP/MAS ${ }^{13} \mathrm{C}$ NMR using BRUKER $400 \mathrm{MHz}$ NMR spectrometer.

\subsubsection{Mechanical stability}

Tensile strength of SPEEK and composite membranes were studied using a Hounsfield universal testing machine. The samples were cut into $5 \mathrm{~mm}$ width and $50 \mathrm{~mm}$ length and the testing was carried out in laboratory atmosphere of $25^{\circ} \mathrm{C} \pm 2{ }^{\circ} \mathrm{C}$ with $100 \%$ relative humidity at a cross head speed of $10 \mathrm{~mm} / \mathrm{min}$ [17].

\subsubsection{Oxidative stability test}

The oxidative stability of all fabricated membranes was investigated by Fenton's test. The membranes were immersed in Fenton's reagent (3\% Hydrogen peroxide solution with $4 \mathrm{ppm}$ of $\mathrm{FeSO}_{4}$ ) at $80{ }^{\circ} \mathrm{C}$ for $144 \mathrm{~h}$. The 
recovered membranes were dried at $90{ }^{\circ} \mathrm{C}$ and weight loss were reported in percentage [30].

\section{Results and discussion}

\subsection{FTIR}

Figure 2 demonstrates the FTIR spectra of TNT, CI-TNT, diNa-W (di sodium tungstate) and W-TNT. The broad absorption bands at $3375 \mathrm{~cm}^{-1}$ and $1640 \mathrm{~cm}^{-1}$ as seen in Fig. $2 a$ was attributed to the stretching and bending vibrations of the surface hydroxyl groups of TNT and bands around $900-500 \mathrm{~cm}^{-1}$ belongs to the Ti-O-Ti skeletal vibration. FTIR results of TNT was in accordance with those of Huang Liu et al. [31]. In the CI-TNT (Fig. 2b) additional absorption peaks at $2988 \mathrm{~cm}^{-1}$ and $1065 \mathrm{~cm}^{-1}$ were observed corresponding to the $\mathrm{C}-\mathrm{H}$ stretching of the chloropropyl group and $\mathrm{Ti}-\mathrm{O}-\mathrm{Si}$ stretching respectively, which reveals that chloropropylsilane group had been successfully grafted on the surface of the TNT. For W-TNT (Fig. 2d) the stretching vibrations $\mathrm{W}=\mathrm{O}$ of tungstic acid was clearly seen at $908 \mathrm{~cm}^{-1}$ which confirms that the titanium oxide nanotubes were functionalized with tungstic acid [28].

Figure 3 shows the FTIR analysis of neat SPEEK and composite membranes SPEEK 2\% W-TNT, SPEEK 4\% W-TNT, SPEEK 6\% W-TNT and SPEEK 8\% W-TNT. In the spectrum of SPEEK (Fig. 3e) there was a broad peak in the high energy region lying between 2100 and $3900 \mathrm{~cm}^{-1}$ which confirms the $\mathrm{OH}$ stretch of $\mathrm{SO}_{3} \mathrm{H}$ group of SPEEK and $\mathrm{C}-\mathrm{H}$ vibrations of the aromatic ring. The peak obtained at $1638 \mathrm{~cm}^{-1}$ corresponds to $C=O$ vibration. Generally, this vibration band occurs at $1750 \mathrm{~cm}^{-1}$. The decreased value was due to the conjugation with the adjacent aromatic ring and

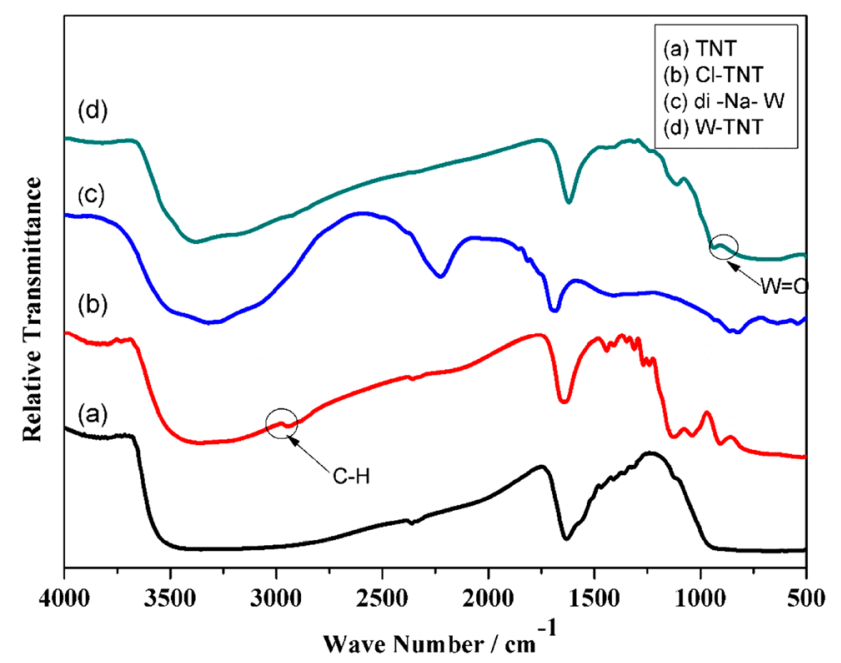

Fig. 2 FTIR spectra of (a) TNT, (b) Cl-TNT, (c) di-Na-W and (d) W-TNT

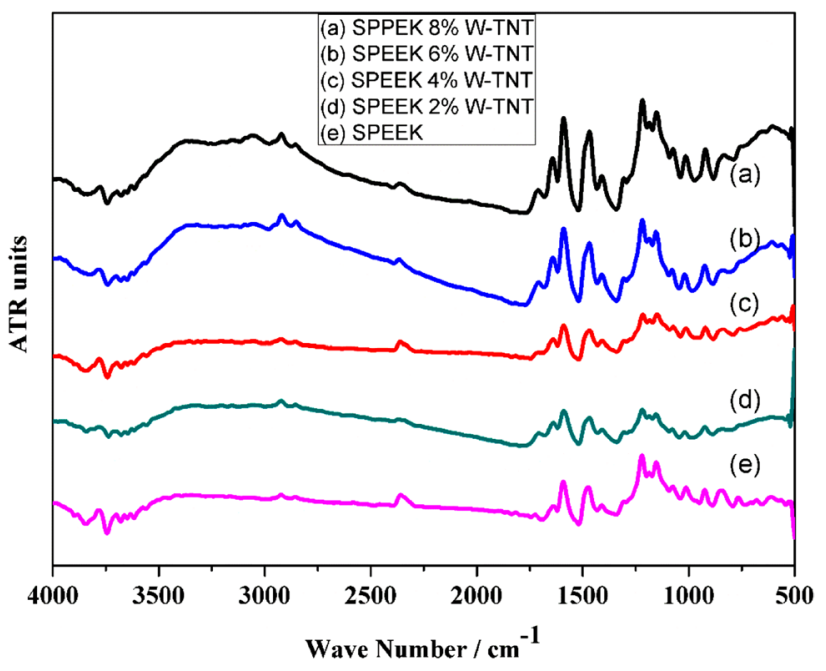

Fig. 3 FTIR spectra of composite membranes and SPEEK

phenolic oxygen. The asymmetric $\mathrm{O}=\mathrm{S}=\mathrm{O}$ stretch of the sulfonic acid occurred close to $1220 \mathrm{~cm}^{-1}$ and the band at $1075 \mathrm{~cm}^{-1}$ was due to the symmetric $\mathrm{O}=\mathrm{S}=\mathrm{O}$ stretch. Whereas, the stretching vibration of $\mathrm{S}-\mathrm{O}$ single bond of sulfonic acid groups was observed $688 \mathrm{~cm}^{-1}$ [32]. The FTIR analysis of the composite membranes revealed that the intensity of the bending vibration of the hydroxyl group at $1610 \mathrm{~cm}^{-1}$ and broadening of the peak between 3200 and $3500 \mathrm{~cm}^{-1}$ increases with the increase in filler content of W-TNT which was due to additional hydroxyl group present in the W-TNT fillers.
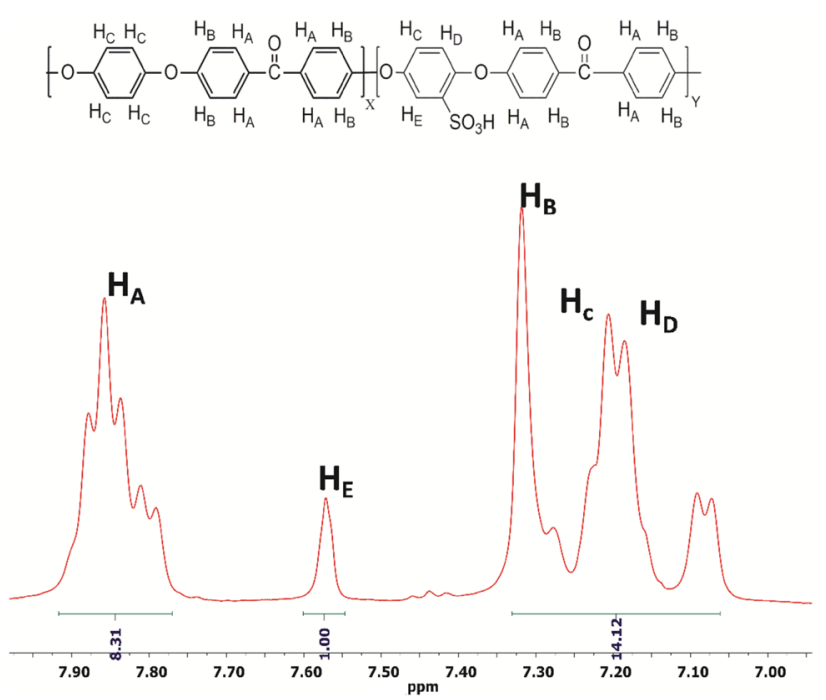

Fig. $4{ }^{1} \mathrm{H}$ NMR spectrum of SPEEK 


\subsection{NMR}

Figure 4 shows the ${ }^{1} \mathrm{H}$-NMR spectrum of SPEEK with the nomenclature of the aromatic protons. Generally, the $\mathrm{H}_{B}$ appears at $7.35 \mathrm{ppm}$ and $\mathrm{H}_{C}$ and $\mathrm{H}_{\mathrm{D}}$ protons appear at $7.20 \mathrm{ppm}$. The multiplet corresponding to $\mathrm{H}_{\mathrm{A}}$ was obtained at $7.85 \mathrm{ppm}$. A peak at $7.60 \mathrm{ppm}$ was assigned to $\mathrm{H}_{\mathrm{E}}$ as a result of sulfonic acid group. The obtained results were found to be in consistence with the previous study performed on SPEEK [33]. Furthermore, degree of sulphonation which is an important parameter in the synthesis of SPEEK

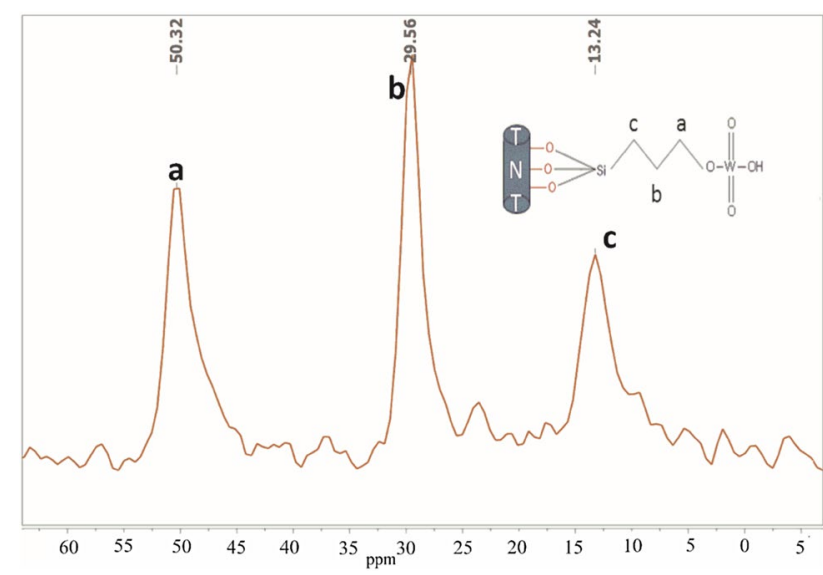

was also estimated from the integral values of the ${ }^{1} \mathrm{H}-\mathrm{NMR}$. The degree of sulfonation was determined through the comparative integration of distinct aromatic signals according to the following Eqs. (4 and 5).

$\frac{n}{12-2 n}=\frac{A H_{E}}{\sum A H_{\text {integrated signals }}}$

$D S=n \times 100 \%$

where $n$ is sulfonation number, $A H_{E}$ is the area of signal of $\mathrm{H}_{\mathrm{E}}$ region, $\mathrm{AH}$ is the area of all other integral signals and DS is the degree of sulfonation. Lower degree of sulphonation results in lesser proton conductivity whereas higher degree of sulphonation results in water swelling of the membrane. Thus, the degree of sulphonation should be moderate. In the present study the calculated degree of sulphonation was found to be $49 \%$. Similar values of sulphonation degree was obtained by Prabhu et al. [25].

The ${ }^{13} \mathrm{C} C P / M A S$ NMR spectrum of W-TNT shows three peaks at $50.32 \mathrm{ppm}, 29.56 \mathrm{ppm}$ and $13.24 \mathrm{ppm}$ as in Fig. 5 which revealed the three types of carbon present in the compound W-TNT. The characteristic signal obtained was due to the bonding of Si with $C(a), C(b)$ and $C(c)$ (propyl chain). The obtained results were similar to that obtained by Kundu et al. on his studies on tungstic acid functionalized SBA-15 [28].

Fig. 5 Solid state CP/MAS ${ }^{13} \mathrm{C}-\mathrm{NMR}$ spectrum of W-TNT

Fig. 6 a SEM image of TNT, $\mathbf{b}$ TEM image of TNT, $\mathbf{c}$ calculation of fringe distance from TEM image, $\mathbf{d}$ TEM image of functionalized TNT
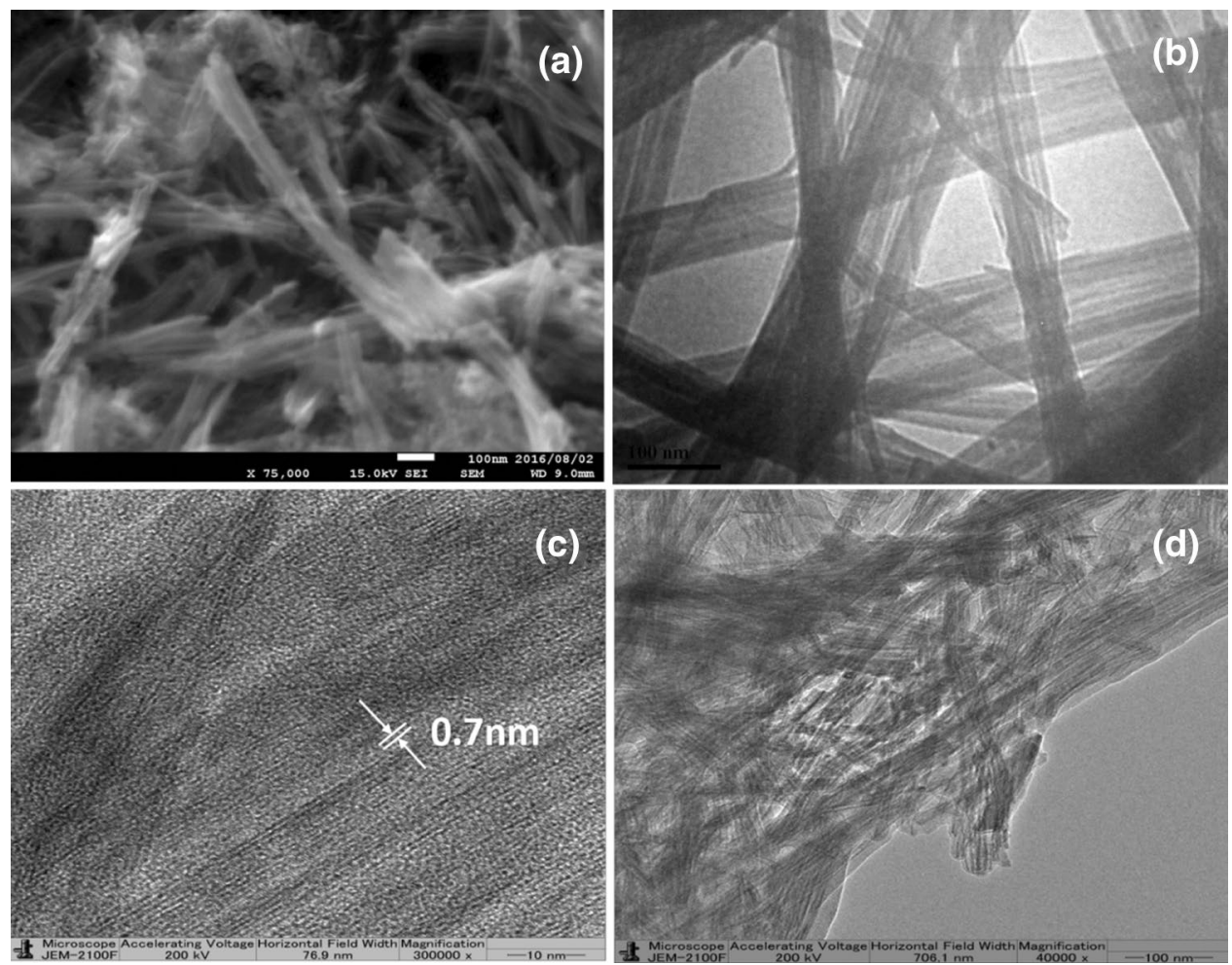


\subsection{Morphology studies}

The surface morphology of the synthesized pure TNT and W-TNT were analysed using SEM and TEM analysis and their images are represented in Fig. 6a-d. The SEM image (6a) shows the nanotube structure of TNT which confirmed the conversion of anatase form of $\mathrm{TiO}_{2}$ into TNT. The observed nanotube structure was found to be in agreement with the previous works [34, 35]. The TEM analysis revealed that the nanotubes were several $\mathrm{nm}$ long and $50-60 \mathrm{~nm}$ in diameter (6b). The obtained results are in congruity with those obtained by Plodinec et al. and Khaled et al. [15, 34, 36]. The fringe distance between the successive titanate layers was found to be $0.7 \mathrm{~nm}$ as shown in (6c). Similar values were also reported in the report by Morgado et al. [37]. In W-TNT (6d), some cloudy appearance was observed over the nanotube structure as a result of functionalization. However, the morphology of the tubes was retained after successive chemical reactions.

The SEM images of SPEEK and composite membranes were shown in Fig. 7. The W-TNT appeared to be well dispersed in the SPEEK matrix in both low as well as high weight percentages. The filler particles appeared to be scattered in a homogenous pattern and clearly embedded in SPEEK matrix. This ensured an effective binding of filler in the polymer matrix thereby producing a good interface interaction and preventing leaching. The W-TNT fillers were dispersed homogenously within the interspaces of the SPEEK polymer chain till $6 \mathrm{wt} \%$. At $8 \mathrm{wt} \%$, the particles were associated with some agglomeration due to higher loading which may affect the proton conduction by blocking effect. The concentration of the filler in the membrane Fig. 7a-e constantly increased from 2 to $8 \%$. The obtained results were similar to the previous nano composites studies $[25,33]$.

\subsection{XRD}

X-ray diffraction (XRD) analysis is an effective method to determine the morphological features. Figure 8 shows the XRD patterns of TNT and W-TNT powders. The pure TNT (Fig. 8a) exhibits four major peaks at $2 \theta=10^{\circ}, 25^{\circ}$, $37^{\circ}$ and $48^{\circ}$ which are the characteristics of a monoclinic structure consisting of layered titanates $\left(\mathrm{H}_{2} \mathrm{Ti}_{3} \mathrm{O}_{7}\right)$ [38]. The XRD patterns of W-TNT (Fig. 8b) did not show much deviation from that of TNT which concludes that the nano tube

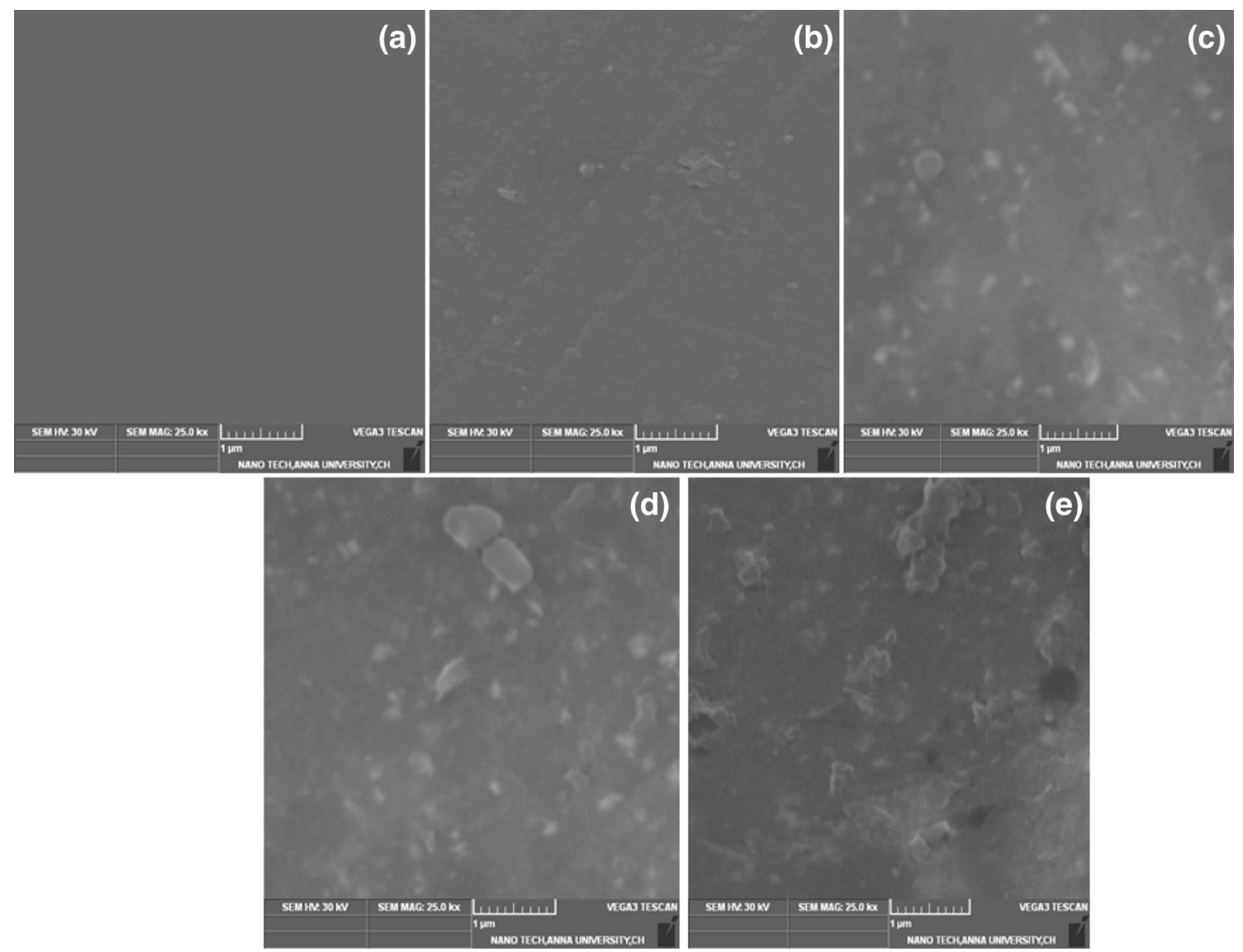

Fig. 7 SEM images of a plain SPEEK membrane, b SPEEK 2\% W-TNT, c SPEEK 4\% W-TNT, d SPEEK 6\% W-TNT, e SPEEK 8\% W-TNT 


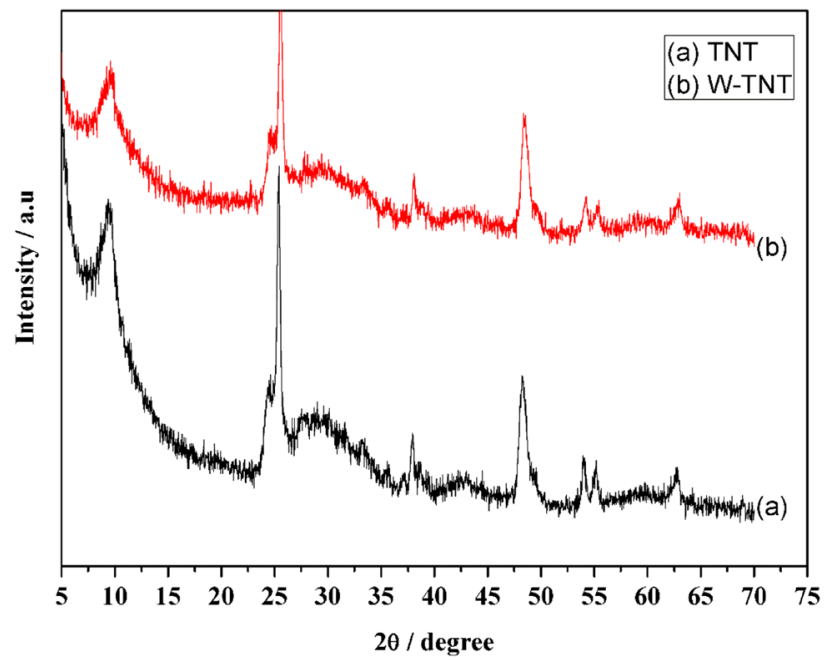

Fig. 8 XRD patterns of (a) TNT, (b) W-TNT

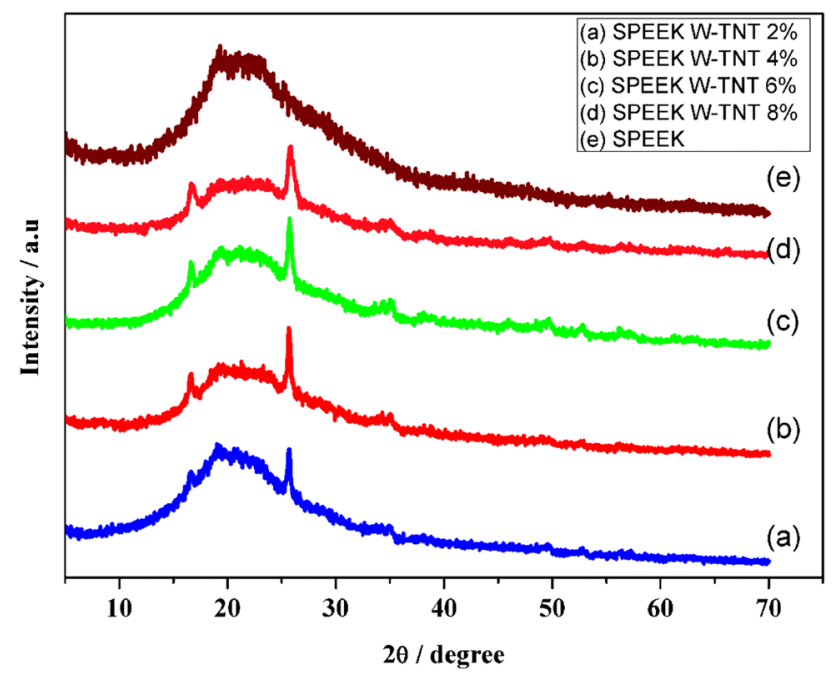

Fig. 9 XRD patterns of composite membranes and SPEEK

morphology was retained even upon functionalization. The effect of change in crystallinity after addition of W-TNT in the SPEEK matrix was also studied by XRD analysis (Fig. 9) The pure SPEEK membrane showed a broad peak centred at $2 \theta$ of $20^{\circ}$ which confirms its semi-crystalline nature [25]. From the XRD profiles it could be observed that the incorporation of W-TNT fillers in the composite membrane had a great influence in the crystalline properties i.e., decreased the intensity of the peak concluding the increase in amorphous nature of the membrane. This increase in amorphous characteristics of the membrane would have facilitated in increasing the conductivity of the membranes (Table 1). It is also worth to note that a linear relationship exists between the amount of filler and the decrease in crystallinity up to $6 \%$. At concentration above $6 \%$, there was no significant change in crystallinity observed due to the optimum loading level (from SEM images Fig. 7). The obtained results were similar to the studies performed by Prabhu et al. and Ayyaru et al. [25, 33].

\subsection{Ion exchange capacity, water uptake and proton conductivity}

lon-exchange capacity is the vital property of ionomers and this property is enhanced with the addition of ion exchange materials [39]. The pure SPEEK membrane showed a IEC of $1.9 \mathrm{meq} \mathrm{g}^{-1}$ as a result of the contribution by sulfonic acid group $\left(\mathrm{SO}_{3} \mathrm{H}\right)$. Increasing the content of W-TNT in the SPEEK membrane increased the ion exchange capacity as shown in Table 1 . This increase in ion exchange was attributed to the ion exchange sites (tungstic acid) present in the TNT which also participated in the ion exchange process in addition to the sulfonic acid group of the SPEEK. Even an addition of $2 \mathrm{wt} \%$ of W-TNT have the capability to increase the IEC to the value of 2.5 meq g $^{-1}$ from 1.9 meq g $^{-1}$ and this implies that large amount of tungstic acid was present in the TNT. A maximum IEC of 3.2 meq $^{-1}$ was exhibited by SPEEK 6\% W-TNT composite membrane. Whereas, SPEEK 8\% W-TNT showed a fall in IEC values which may due to the agglomeration of the filler particles that blocked the ion exchange groups from participating in the ion exchange process [40].

Water molecules present inside the membrane play a significant role in proton conduction. Higher the amount of water uptake by membrane leads to facilitation of proton diffusion. Generally, the water uptake of membranes increased with increase in IEC, owing to the increase in
Table 1 Comparison of water uptake, conductivity and lon exchange capacity (IEC) of (W-TNT) nanotubes-SPEEK composite membranes

\begin{tabular}{lllll}
\hline Membrane type & Thickness $(\mu \mathrm{m})$ & Water uptake $(\%)$ & $\begin{array}{l}\text { Conductivity } \\
\left(\times 10^{-3} \mathrm{~S} \mathrm{~cm}^{-1}\right)\end{array}$ & IEC $\left(\mathrm{meq} \mathrm{g}^{-1}\right)$ \\
\hline SPEEK & $123 \pm 5$ & 13.42 & 6.43 & 1.93 \\
SPEEK 2\% W-TNT & $121 \pm 3$ & 15.26 & 7.37 & 2.55 \\
SPEEK 4\% W-TNT & $119 \pm 5$ & 17.73 & 8.64 & 2.87 \\
SPEEK 6\% W-TNT & $118 \pm 3$ & 19.24 & 9.63 & 3.28 \\
SPEEK 8\% W-TNT & $119 \pm 5$ & 18.72 & 9.32 & 2.94 \\
\hline
\end{tabular}


hydrophilicity. The hydrophilic W-TNT fillers improved the water holding capacity of the SPEEK membranes. Hence, values of water uptake were higher for all composite membranes than the pure SPEEK (Table 1) The observed values were found to increase not only due to increased IEC but also due to the hollow nature of TNT which are beneficial in water retention and adsorption ability. The maximum water uptake value was shown by SPEEK $6 \%$ W-TNT composite membrane (19.24\%) and the value is more affordable for membranes used for fuel cell working under humid conditions.

The aim of incorporating W-TNT filler particles into SPEEK membrane was to enhance the proton transfer within the composite membrane and this can be attained by two ways 1 . The hollow nature of the TNT could retain large number of water molecule inside the membrane (due to its tubular morphology) that boost up the water mediated pathways for proton conduction (Grotthuss mechanism) [41]. 2. The ion exchange group (tungstic acid) present in the W-TNT can also involve in the proton exchange process (hopping mechanism) in addition to the sulfonate group of the SPEEK. This combined effect makes the composite membrane to be less resistant for the movement of protons through it [33]. Hence all the composite membranes were observed to show higher conductivity than the plain membrane. The uniform mixing of the filler with the polymer membrane had resulted in increase of amorphous nature (XRD profile Fig. 9) which further helped in improving the proton conductivity. From Table 1, the membrane with $6 \%$ filler concentration exhibited the maximum conductivity when compared with other membranes. A slight dip in conductivity was observed for $8 \mathrm{wt} \%$ of filler containing membrane due to

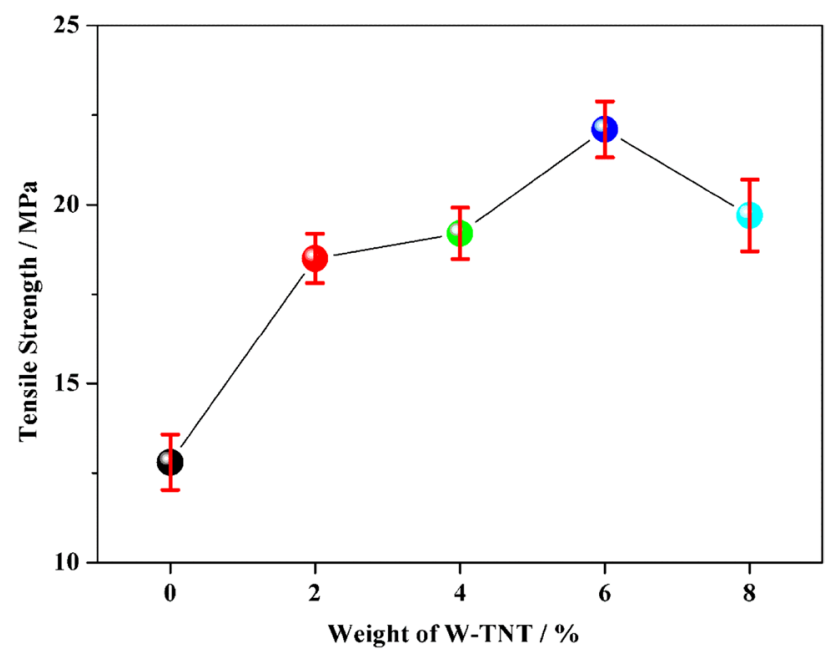

Fig. 10 Tensile strength of SPEEK and composite membranes the aggregation of nanotubes which hindered the ionic channel in the polymer membrane.

\subsection{Tensile strength}

The tensile strength of SPEEK and SPEEK W-TNT composite membranes are shown in Fig. 10. It was evident that composite membranes have a higher tensile strength than SPEEK membrane due to the addition of W-TNT filler. The increase in tensile strength was due to two factors, first, the membrane had become reinforced with these inorganic fillers and second, the hydrophilic nature of the filler increased the water uptake and thereby resulting in increased elastic property. The optimum tensile strength of 22.1 MPa was obtained for SPEEK 6\% W-TNT which was due to the maximum uniform distribution of W-TNT without any agglomeration that helped to disperse the applied stress throughout the membrane. When the proportion of W-TNT exceeds this optimum level i.e., $8 \%$ the strength of the membrane decreased to $19.6 \mathrm{MPa}$ as a result of stress concentration at the interface of the W-TNT/SPEEK composite owing to the higher concentration of fillers [42].

\subsection{Oxidative stability}

The chemical oxidation stability of the membranes is one of the crucial requirements for the durability and performance of fuel cells which was estimated by Fenton's reagent method. The pure SPEEK and all the fabricated composites membranes showed a weight loss less than $4 \%$ (Fig. 11) after immersing in Fenton's reagent for $144 \mathrm{~h}$ which revealed a good chemical stability. The decrease in the stability of the membrane may be due to the breakdown the of ether linkages of the SPEEK polymer chain [29].

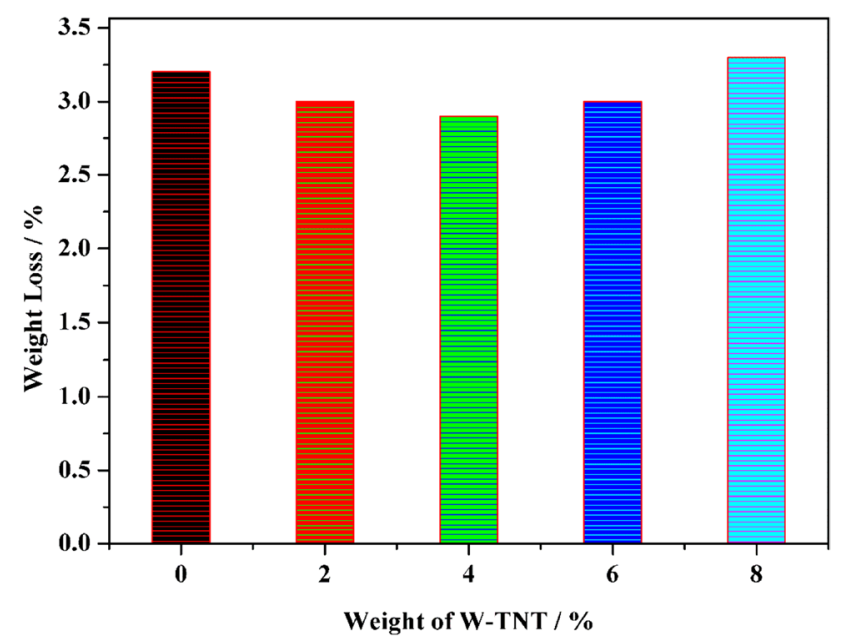

Fig. 11 Oxidative stability of SPEEK and composites membranes 


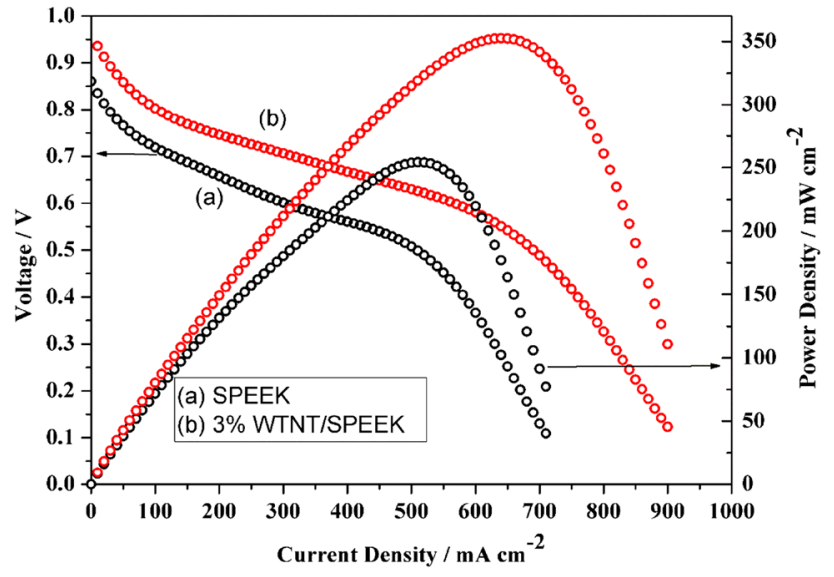

Fig. 12 Fuel cell performance of (a) SPEEK and (b) SPEEK 6\% W-TNT measured at $80^{\circ} \mathrm{C}$

\subsection{Fuel cell performance}

The polarization curves of SPEEK and SPEEK 6\% W-TNT in an in-house built fuel cell with Pt electrodes operated at $80^{\circ} \mathrm{C}$ are shown in Fig. 12. The performance study revealed that the SPEEK 6\% W-TNT showed higher OCV of $0.945 \mathrm{~V}$ than the SPEEK membrane (0.845 V) due to the denser composite membrane than the neat SPEEK which may lower the fuel cross-over behaviour. From the polarization curve it was also interfered that the power density and current density of SPEEK $6 \%$ W-TNT were $352 \mathrm{~mW} \mathrm{~cm}^{-2}$ and $690 \mathrm{~mA} \mathrm{~cm}^{-2}$ respectively. Whereas SPEEK membrane showed a power density of $245 \mathrm{~mW} \mathrm{~cm}^{-2}$ and current density of $540 \mathrm{~mA} \mathrm{~cm}^{-2}$. The higher hydroxide conductivity of the SPEEK $6 \%$ W-TNT membranes may be attributed to the presence of additional ion exchange sites and increased degree of water uptake in-turn leading to higher fuel cell performance.

\section{Conclusion}

The study revealed the role of functionalized TNT in SPEEK composite membranes as electrolyte for PEM fuel cells. The synthesized W-TNT and composite membranes were characterized by SEM, TEM, XRD, FTIR, NMR and their physico- chemical properties were studied. In the presence of W-TNT, SPEEK composites exhibited better properties such as increased water uptake, proton conductivity, ion exchange capacity and power density compared with plain SPEEK membranes. The membrane with $6 \mathrm{wt} \%$ of W-TNT showed the best results compared to other composite membranes. Upon testing in fuel cell setup, the composite membrane SPEEK 6\% W-TNT exhibited a maximum power density of $352 \mathrm{~mW} \mathrm{~cm}^{-2}$. Beyond $6 \mathrm{wt} \%$ of the filler W-TNT, agglomeration and blocking effect of the nanotubes reduced the proton conductivity. The results showed that the addition of W-TNT fillers in the SPEEK matrix increased the fuel cell performance due to improved surface area for active sites (protonation), water uptake, ion exchange capacity and proton conductivity. Hence, the present study indicates that the use of hollow natured TNTs along with the bonded ion exchange groups (tungstic acid) as fillers in the composite membranes assisting both Grotthuss and hopping mechanisms of ionic conductivity forms an excellent electrolyte for PEMFCs.

Acknowledgements The authors VE and DS thank Council of Scientific and Industrial Research (CSIR), New Delhi, India (Vide letter No. 01(2452)/11/EMR-11, letter dated 16.05.2011) and SERB New Delhi, India (Vide file No. EMR/2016/005615) for the financial support. The authors TD, KAA and JK would like to express their gratitude towards Center for Technology Development and Transfer (CTDT) Anna University Chennai for providing financial support (student innovative project).

\section{Compliance with ethical standards}

Conflict of interest The authors declare that they have no conflict of interest.

\section{References}

1. Prabhu NV, Sangeetha D (2014) Characterization and performance study of sulfonated poly ether ether ketone $/ \mathrm{Fe}_{3} \mathrm{O}_{4}$ nano composite membrane as electrolyte for microbial fuel cell. Chem Eng J 243:564-571. https://doi.org/10.1016/j.cej.2013.12.103

2. Jothi PR, Dharmalingam S (2014) An efficient proton conducting electrolyte membrane for high temperature fuel cell in aqueous-free medium. J Membr Sci 450:389-396. https://doi. org/10.1016/j.memsci.2013.09.034

3. Rahnavard A, Rowshanzamir S, Parnian MJ, Amirkhanlou GR (2015) The effect of sulfonated poly (ether ether ketone) as the electrode ionomer for self-humidifying nanocomposite proton exchange membrane fuel cells. Energy 82:746-757. https://doi. org/10.1016/j.energy.2015.01.086

4. Gashoul F, Parnian MJ, Rowshanzamir S (2017) A new study on improving the physicochemical and electrochemical properties of SPEEK nanocomposite membranes for medium temperature proton exchange membrane fuel cells using different loading of zirconium oxide nanoparticles. Int J Hydrog Energy 42:590-602. https://doi.org/10.1016/j.ijhydene.2016.11.132

5. De Aguiar LCV, Filho FGDR, Kawaguti CA (2016) Synthesis of poly (ether ether) ketone sulfonated membrane with tin dioxide particles. J Mater Sci Chem Eng 4:49-60. https://doi.org/10.4236/ msce.2016.42006

6. Won J, Choi SW, Kang YS, Ha HY, Oh IH, Kim HS, Kim KT, Jo WH (2003) Structural characterization and surface modification of sulfonated polystyrene-(ethylene-butylene)-styrene triblock proton exchange membranes. J Membr Sci 214:245-257. https ://doi.org/10.1016/S0376-7388(02)00555-0

7. Ghassemi H, Subbaraman R, Brockman C, Pyle B, Zawodzinski T Jr (2008) Proton exchange membrane based on sulfonated 
polyethersulfone for $\mathrm{H}_{2}$ /air and direct methanol fuel cells. ECS Trans 16:689-697. https://doi.org/10.1149/1.2981904

8. Guo X, Fang J, Watari T, Tanaka K, Kita H, Okamoto KI (2002) Novel sulfonated polyimides as polyelectrolytes for fuel cell application. 2. Synthesis and proton conductivity of polyimides from 9,9-bis(4-aminophenyl)fluorene-2,7-disulfonic acid. Macromolecules 35:6707-6713. https://doi.org/10.1021/ma020260w

9. Mangiatordi GF, Butera V, Russo N, Laage D, Adamo C (2012) Charge transport in poly-imidazole membranes: a fresh appraisal of the Grotthuss mechanism. Phys Chem Chem Phys 14:10910-10918. https://doi.org/10.1039/c2cp23727j

10. Jang H, Sutradhar SC, Yoo J, Ha J, Pyo J, Lee C, Ryu T, Kim W (2016) Synthesis and characterization of sulfonated poly(phenylene) containing a non-planar structure and dibenzoyl groups. Energies 9:1-11. https://doi.org/10.3390/en9020115

11. Shyuan LK, Tan EL, Wan Daud WR, Mohamad AB (2013) Synthesis and characterization of sulfonated polybenzimidazole (SPBI) copolymer for polymer exchange membrane fuel cell. Adv Mater Res. 860-863:803-806. https://doi.org/10.4028/www.scientific .net/AMR.860-863.803

12. Liu B, Robertson GP, Kim DS, Guiver MD, Hu W, Jiang Z (2007) Aromatic poly(ether ketone)s with pendant sulfonic acid phenyl groups prepared by a mild sulfonation method for proton exchange membranes. Macromolecules 40:1934-1944. https:// doi.org/10.1021/ma061705+

13. Marani D, D'Epifanio A, Traversa E, Miyayama M, Licoccia S (2010) Titania nanosheets (TNS)/sulfonated poly ether ether ketone (SPEEK) nanocomposite proton exchange membranes for fuel cells. Chem Mater 22:1126-1133. https://doi.org/10.1021/cm902 $405 p$

14. Hickner MA, Ghassemi H, Kim YS, Einsla BR, McGrath JE (2004) Alternative polymer systems for proton exchange membranes (PEMs). Chem Rev 104:4587-4611. https://doi.org/10.1021/cr020 $711 a$

15. Plodinec $M$, Gajović $A$, Iveković $D$, Tomašić $N$, Zimmermann $B$, Macan J, Haramina T, Su DS, Willinger M (2014) Study of thermal stability of (3-aminopropyl)trimethoxy silane-grafted titanate nanotubes for application as nanofillers in polymers. Nanotechnology. https://doi.org/10.1088/0957-4484/25/43/435601

16. Vinodh R, Purushothaman M, Sangeetha D (2011) Novel quaternized polysulfone/ $\mathrm{ZrO}_{2}$ composite membranes for solid alkaline fuel cell applications. Int J Hydrog Energy 36:7291-7302. https:// doi.org/10.1016/j.ijhydene.2011.03.056

17. Vijayakumar E, Sangeetha D (2015) A quaternized mesoporous silica/polysulfone composite membrane for an efficient alkaline fuel cell application. RSC Adv 5:42828-42835. https://doi.org/10.1039/ c5ra04144a

18. Scipioni R, Gazzoli D, Teocoli F, Palumbo O, Paolone A, Ibris N, Brutti S, Navarra MA (2014) Preparation and characterization of nanocomposite polymer membranes containing functionalized $\mathrm{SnO}_{2}$ additives. Membranes (Basel) 4:123-142. https://doi.org/10.3390/ membranes4010123

19. Sonpingkam S, Pattavarakorn D (2014) Mechanical properties of sulfonated poly (ether ether ketone) nanocomposite membranes. Int J Chem Eng Appl 5:181-185. https://doi.org/10.7763/IJCEA .2014.V5.374

20. Rajalakshmi N, Lakshmi N, Dhathathreyan KS (2008) Nano titanium oxide catalyst support for proton exchange membrane fuel cells. Int J Hydrog Energy 33:7521-7526. https://doi.org/10.1016/j.ijhyd ene.2008.09.032

21. Alberti G, Casciola M (2003) Composite membranes for mediumtemperature PEM fuel cells. Annu Rev Mater Res 33:129-154. https ://doi.org/10.1146/annurev.matsci.33.022702.154702

22. Ioroi T, Siroma Z, Fujiwara N, Yamazaki SI, Yasuda K (2005) Sub-stoichiometric titanium oxide-supported platinum electrocatalyst for polymer electrolyte fuel cells. Electrochem Commun 7:183-188. https://doi.org/10.1016/j.elecom.2004.12.007
23. Qiao Y, Bao SJ, Li CM, Cui XQ, Lu ZS, Guo J (2008) Nanostructured polyaniline/titanium dioxide composite anode for microbial fuel cells. ACS Nano 2:113-119. https://doi.org/10.1021/nn700102s

24. Nonjola PT, Mathe MK, Modibedi RM (2013) Chemical modification of polysulfone: composite anionic exchange membrane with $\mathrm{TiO}_{2}$ nano-particles. Int J Hydrog Energy 38:5115-5121. https:// doi.org/10.1016/j.ijhydene.2013.02.028

25. Venkatesan PN, Dharmalingam S (2015) Effect of cation transport of SPEEK - rutile $\mathrm{TiO}_{2}$ electrolyte on microbial fuel cell performance. J Membr Sci 492:518-527. https://doi.org/10.1016/j. memsci.2015.06.025

26. Jun $Y$, Zarrin H, Fowler M, Chen Z (2011) Functionalized titania nanotube composite membranes for high temperature proton exchange membrane fuel cells. Int J Hydrog Energy 36:6073-6081. https://doi.org/10.1016/j.ijhydene.2011.02.030

27. Nakahira A, Kato W, Tamai M, Isshiki T, Nishio K, Aritani H (2004) Synthesis of nanotube from a layered $\mathrm{H}_{2} \mathrm{Ti}_{4} \mathrm{O}_{9} \cdot \mathrm{H}_{2} \mathrm{O}$ in a hydrothermal treatment using various titania sources. J Mater Sci 39:42394245. https://doi.org/10.1023/B:JMSC.0000033405.73881.7c

28. Kundu SK, Mondal J, Bhaumik A (2013) Tungstic acid functionalized mesoporous SBA-15: a novel heterogeneous catalyst for facile one-pot synthesis of 2-amino-4H-chromenes in aqueous medium. Dalt Trans 42:10515-10524. https://doi.org/10.1039/c3dt50947h

29. Venkatesan PN, Dharmalingam S (2015) Development of cation exchange resin-polymer electrolyte membranes for microbial fuel cell application. J Mater Sci 50:6302-6312. https://doi. org/10.1007/s10853-015-9167-x

30. Mack F, Aniol K, Ellwein C, Kerres J, Zeis R (2015) Novel phosphoric acid-doped PBI-blends as membranes for high-temperature PEM fuel cells. J Mater Chem A 3:10864-10874. https://doi.org/10.1039/ c5ta01337b

31. Liu H, Zhang Y, Yang H, Xiao W, Sun L (2016) Study on synthesis and photocatalytic activity of porous titania nanotubes. Adv Mater Sci Eng. https://doi.org/10.1155/2016/3532817

32. Gaowen Z, Zhentao Z (2005) Organic/inorganic composite membranes for application in DMFC. J Membr Sci 261:107-113. https ://doi.org/10.1016/j.memsci.2005.03.036

33. Ayyaru S, Dharmalingam S (2015) A study of influence on nanocomposite membrane of sulfonated $\mathrm{TiO}_{2}$ and sulfonated polystyrene-ethylene-butylene-polystyrene for microbial fuel cell application. Energy 88:202-208. https://doi.org/10.1016/j.energ y.2015.05.015

34. Van Viet P, Van Hieu L, Thi CM (2016) The directed preparation of $\mathrm{TiO}_{2}$ nanotubes film on FTO substrate via hydrothermal method for gas sensing application. AIMS Mater Sci 3:460-469. https://doi. org/10.3934/matersci.2016.2.460

35. Manfroi DC, Dos Anjos A, Cavalheiro AA, Perazolli LA, Varela JA, Zaghete MA (2014) Titanate nanotubes produced from microwave-assisted hydrothermal synthesis: photocatalytic and structural properties. Ceram Int 40:14483-14491. https://doi. org/10.1016/j.ceramint.2014.07.007

36. Khaled SMZ, Miron RJ, Hamilton DW, Charpentier PA, Rizkalla AS (2010) Reinforcement of resin based cement with titania nanotubes. Dent Mater 26:169-178. https://doi.org/10.1016/j.denta I.2009.09.011

37. Morgado E, de Abreu MAS, Moure GT, Marinkovic BA, Jardim PM, Araujo AS (2007) Effects of thermal treatment of nanostructured trititanates on their crystallographic and textural properties. Mater Res Bull 42:1748-1760. https://doi.org/10.1016/j.materresbu II.2006.11.020

38. Chen Q, Du GH, Zhang S, Peng LM (2002) The structure of trititanate nanotubes. Acta Crystallogr Sect B Struct Sci 58:587-593. https ://doi.org/10.1107/S0108768102009084

39. Elumalai V, Dharmalingam S (2016) Synthesis characterization and performance evaluation of ionic liquid immobilized SBA-15/ quaternised polysulfone composite membrane for alkaline fuel 
cell. Microporous Mesoporous Mater 236:260-268. https://doi. org/10.1016/j.micromeso.2016.09.007

40. Movil O, Frank L, Staser JA (2015) Graphene oxide-polymer nanocomposite anion-exchange membranes. J Electrochem Soc 162:F419-F426. https://doi.org/10.1149/2.0681504jes

41. Şengül E, Erdener H, Akay RG, Yücel H, Baç N, Eroğlu I (2009) Effects of sulfonated polyether-etherketone (SPEEK) and composite membranes on the proton exchange membrane fuel cell (PEMFC) performance. Int J Hydrog Energy 34:4645-4652. https ://doi.org/10.1016/j.ijhydene.2008.08.066
42. Peera SG, Meenakshi S, Gopi KH, Bhat SD, Sridhar P, Pitchumani $S$ (2013) Impact on the ionic channels of sulfonated poly(ether ether ketone) due to the incorporation of polyphosphazene: a case study in direct methanol fuel cells. RSC Adv 3:14048-14056. https://doi.org/10.1039/c3ra41508b

Publisher's Note Springer Nature remains neutral with regard to jurisdictional claims in published maps and institutional affiliations. 